\title{
Campo Multiplicativo: Análise de Tratamentos e Conversões nos Anos Iniciais do Ensino Fundamental
}

\author{
Multiplicative field: Treatments and Conversion Analysis in Years \\ Elementary School Initials
}

Neiva Ignês Grando
neiva@upf.br

Flávia de Andrade Niemann

flavia.niemann@terra.com.br

\begin{abstract}
Resumo
A proposta deste artigo refere-se ao uso de registros de representação semiótica nos anos iniciais do ensino fundamental. O estudo realizado em classes de $4^{\circ}$ e $5^{\circ}$ ano do ensino fundamental tem como objetivo investigar as possibilidades de potencialização da aprendizagem dos conceitos matemáticos do campo multiplicativo em sala de aula. $\mathrm{Na}$ análise constatou-se a existência de uma diversidade de tratamentos utilizados na resolução de situações-problema envolvendo as operações de divisão e multiplicação e a dificuldade dos estudantes na identificação do significado dos termos da multiplicação ao realizarem a conversão da linguagem aritmética para a língua natural. Como suportes teóricos foram utilizados pressupostos das teorias de Gérard Vergnaud e Raymond Duval.
\end{abstract}

Palavras-chave: educação matemática; campo multiplicativo; registros de representação semiótica.

\begin{abstract}
The purpose of this paper refers to the use of registers of semiotic representation in the early years of elementary school. The study in classes 4th and 5th year of elementary school aims to investigate the possibilities for enhancement of learning mathematical concepts from the field multiplicative classroom. The analysis revealed the existence of a variety of treatments used in resolving problem situations involving the operations of multiplication and division and the difficulty of students in terms of identifying the meaning of multiplication to perform the conversion of language into natural language arithmetic. As media theorists were assumptions of the theories of Gérard Vergnaud and Raymond Duval.
\end{abstract}

Keywords: mathematics education; multiplicative field; registers of semiotic representation.

\section{Introdução}

O presente artigo apresenta aspectos teórico-metodológicos do processo de ensino e aprendizagem dos conceitos relacionados ao campo multiplicativo, com o objetivo de levantar possibilidades para a construção de propostas pedagógicas que priorizem a compreensão dos conteúdos matemáticos abordados nos anos iniciais do ensino fundamental. 
Para isso, é apresentada parte de uma pesquisa realizada com turmas do $4^{\circ}$ e $5^{\circ}$ ano do ensino fundamental de uma instituição privada de ensino, de Passo Fundo/RS, visando analisar as transformações de registros de representação semiótica utilizadas pelos estudantes na resolução de situações do campo multiplicativo.

O trabalho com o campo multiplicativo é realizado na escola desde a Educação Infantil, cujo objetivo é realizar aproximações sucessivas dos significados da operação de multiplicação e divisão através da resolução de problemas. Contudo, a sistematização de alguns conceitos matemáticos do campo multiplicativo acontece no $4^{\circ}$ ano, quando está previsto o trabalho com as regularidades das tabuadas, a formulação de alguns conceitos do campo multiplicativo (proporcionalidade, configuração retangular, combinatória) e o funcionamento do algoritmo convencional da multiplicação.

Os sujeitos desta pesquisa são 10 estudantes da turma do $4^{\circ}$ ano e 17 estudantes da turma do $5^{\circ}$ ano, aos quais foi aplicado um instrumento contendo seis situações-problema do campo multiplicativo, no início do ano letivo.

Neste trabalho será apresentada a análise das produções referentes a três situações-problema contidas no instrumento e resolvidas pelos estudantes do $5^{\circ}$ ano. As duas primeiras situações pertencem à categoria denominada por Gérard Vergnaud como isomorfismo de medida e a terceira envolve a elaboração de situações-problema, na forma de enunciados, a partir de duas sentenças matemáticas que expressam multiplicações. Nas duas primeiras situações foram analisados os tratamentos utilizados pelos estudantes e os conceitos matemáticos implicados na sua utilização. Na terceira situação foram analisadas as conversões realizadas, da linguagem aritmética para a língua natural, observando o sentido dado aos termos da multiplicação (multiplicando, multiplicador e produto). Para identificar os sujeitos da pesquisa, usou-se a letra inicial da palavra estudante, maiúscula, seguida de dois dígitos que indicam o aluno, classificado por ordem alfabética.

A análise foi orientada, principalmente por pressupostos da Teoria dos Campos Conceituais de Gérard Vergnaud e da Teoria dos Registros de Representação Semiótica de Raymond Duval. 


\section{Aportes teóricos}

Nos últimos anos intensificaram-se os estudos sobre as propostas pedagógicas para o ensino da matemática na escola. Os Parâmetros Curriculares Nacionais $(\mathrm{PCNs})^{1}$ do ensino fundamental destacam o papel da Matemática como crucial “[...] na formação de capacidades intelectuais, na estruturação do pensamento, na agilização do raciocínio dedutivo do aluno, na sua aplicação a problemas, situações da vida cotidiana e atividades do mundo do trabalho" (BRASIL, 1997, p. 29).

Nessa perspectiva, emergem novas possibilidades teórico-metodológicas para o desenvolvimento de práticas pedagógicas relacionadas ao ensino de conceitos matemáticos da operação de multiplicação e divisão nos anos iniciais do ensino fundamental, que por muito tempo esteve relacionada ao ensino da tabuada, dos algoritmos convencionais e suas propriedades.

Com a orientação explicitada nos PCNs de que o trabalho com a multiplicação e a divisão deveria ser realizado por meio de um conjunto de problemas, devido às estreitas conexões entre as situações que os envolvem (BRASIL, 1997), modifica-se a perspectiva do ensino de conceitos relacionados a essas operações, para o ensino de conceitos ligados a um campo conceitual, o campo multiplicativo.

Esta concepção tem relação com a Teoria dos Campos Conceituais elaborada por Gérard Vergnaud, o qual considera que uma das vantagens de considerar um campo conceitual como um conjunto de situações, "é a de permitir gerar uma classificação baseada na análise das tarefas cognitivas e nos procedimentos que podem ser postos em jogo em cada uma delas" (VERGNAUD, 1990, p. 7-8, tradução nossa).

Assim, os conceitos relacionados à multiplicação e divisão estão contidos em um conjunto de situações denominado campo conceitual multiplicativo, “cujo tratamento implica uma ou várias multiplicações ou divisões e o conjunto de conceitos e teoremas que permitem analisar estas situações [...]" (VERGNAUD, 1990, p. 8, tradução nossa).

As situações pertencentes ao campo conceitual multiplicativo, ou seja, problemas cuja solução é definida por meio de uma multiplicação ou divisão, segundo Vergnaud (2014) são 
classificados em duas grandes categorias de relações: isomorfismo de medidas e produto de medidas. Essas categorias são subdivididas em classes conforme a posição da incógnita na situação, os tipos de grandezas (contínuas e descontínuas) e o conjunto a que os números pertencem.

De acordo com Vergnaud (1990) não se pode teorizar a aprendizagem da matemática somente a partir do simbolismo ou das situações. É necessário considerar o sentido das situações e dos símbolos e levar em conta a ação do sujeito na situação e a organização de sua conduta. Portanto, a utilização da representação simbólica é um dos elementos que compõem a aprendizagem de um conceito matemático.

Nesse contexto, a Teoria dos Registros de Representação Semiótica, de Raymond Duval, busca evidenciar a importância de diferenciar o objeto matemático de suas representações, além de contextualizar, do ponto de vista cognitivo, a atividade matemática através da variedade de representações semióticas.

Para Duval (2009), as atividades cognitivas relacionadas à aprendizagem da Matemática estão ligadas ao uso de registros de representação, isto é, de sistemas semióticos como língua natural, sistemas de escrita de números, escritas algébricas, notações simbólicas formais, figuras geométricas planas ou em perspectiva, gráficos cartesianos, diagramas. De acordo com o autor, as representações mentais não podem ser consideradas independentes das representações semióticas, ou seja, a apreensão conceitual de um objeto matemático depende da produção e coordenação de diferentes representações semióticas.

Na concepção de Duval (2009), as atividades cognitivas relacionadas à aprendizagem da Matemática estão ligadas ao uso de registros de representação, isto é, de sistemas semióticos como língua natural, sistemas de escrita de números, escritas algébricas, notações simbólicas formais, figuras geométricas planas ou em perspectiva, gráficos cartesianos, diagramas. Assim, para o autor, as representações mentais não podem ser consideradas independentes das representações semióticas, ou seja, a apreensão conceitual de um objeto matemático depende da produção e coordenação de diferentes representações semióticas.

Nesse sentido, a análise da utilização de diferentes registros de representações semióticas, durante a realização de uma atividade matemática, implica em identificar dois tipos de transformações de representações: os tratamentos e as conversões (DUVAL, 2009). 
O tratamento é a transformação de uma representação semiótica em outra, em que esta se refere às operações dentro de um mesmo sistema semiótico. No exemplo a seguir, essa transformação de representação pode ser reconhecida na resolução de um mesmo cálculo de multiplicação, "12 x 8”, em cada um dos diferentes tratamentos.

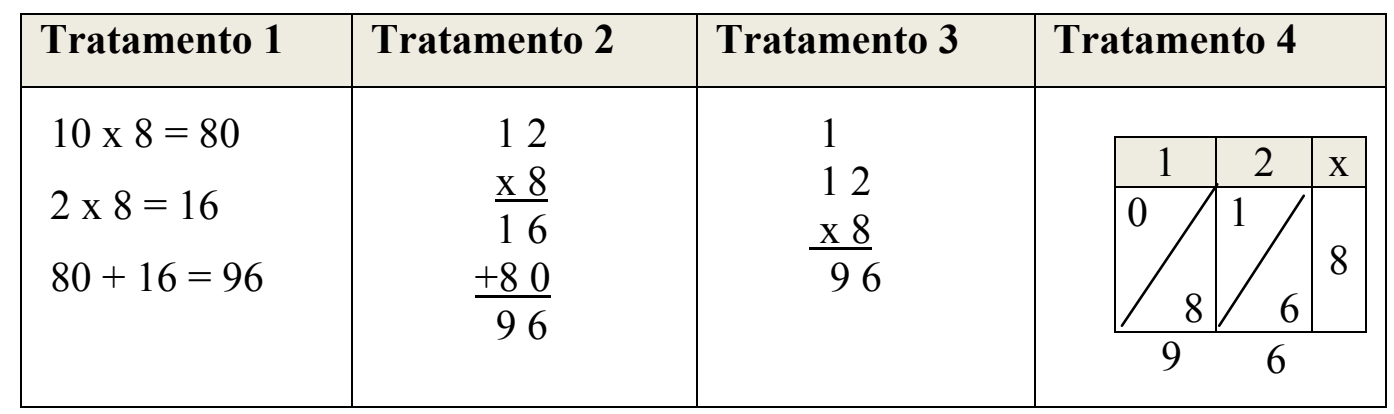

Por outro lado, a conversão de uma representação se refere às operações em que o registro inicial é transformado em outro registro, quando se opera com sistemas semióticos diferentes. Por exemplo, ao utilizar " 24 × 6" para representar a situação-problema "as cadeiras de uma sala estão dispostas em 24 fileiras com 6 cadeiras cada uma, quantas cadeiras há na sala?”, foi realizada uma conversão do registro dado na língua natural para o registro dado na linguagem aritmética.

Nessa perspectiva, as transformações de registros de representações semióticas, sejam em caráter de tratamento ou de conversão, demonstram aspectos diferentes de um mesmo conceito matemático, portanto a possibilidade de compreensão integral de um determinado conceito se amplia e o aluno avança significativamente ao envolver um repertório cada vez maior de representações matemáticas.

Diante desses pressupostos, é possível refletir e projetar algumas possibilidades para mudanças qualitativas na abordagem do ensino de conteúdos referentes ao campo multiplicativo e ao uso dos registros de representação semiótica nos anos iniciais do ensino fundamental.

\section{Análise de registros de representação semiótica em situações do campo multiplicativo}

A participação ativa do estudante no processo de aquisição de conhecimentos matemáticos, desde os anos iniciais do ensino fundamental, pode possibilitar ao trabalho do professor em sala de aula a problematização sobre as diferentes estratégias de cálculo e interpretações pessoais dos alunos a respeito dos significados das operações aritméticas elementares (adição, subtração, multiplicação e divisão). 
Por isso, a análise e interpretação das representações produzidas pelas crianças ao resolverem e elaborarem enunciados de situações-problema de um campo conceitual é muito importante para a formulação de propostas pedagógicas que visem a compreensão em matemática.

Nesse sentido, a pesquisa realizada busca analisar as tranformações de registros de representação semiótica utilizadas pelos estudantes ao resolverem situações-problema do campo multiplicativo.

Durante a análise das produções, foi verificado que todos os estudantes utilizaram registros simbólicos (linguagem aritmética) para resolver as três primeiras situações propostas.

Nessa primeira situação, treze estudantes utilizaram o algoritmo convencional da multiplicação como tratamento e quatro $\left(\mathrm{E}_{03} ; \mathrm{E}_{06} ; \mathrm{E}_{10} ; \mathrm{E}_{12}\right)$ utilizaram estratégias não convencionais.

$1^{a}$ situação: Em uma caixa de Kinder tem 3 ovos. Uma loja comprou 135 caixas. Quantos ovos a loja comprou?

A seguir são apresentados três diferentes exemplos de tratamentos não convencionais.

Tratamento $1\left(\mathrm{E}_{06}\right)$ :

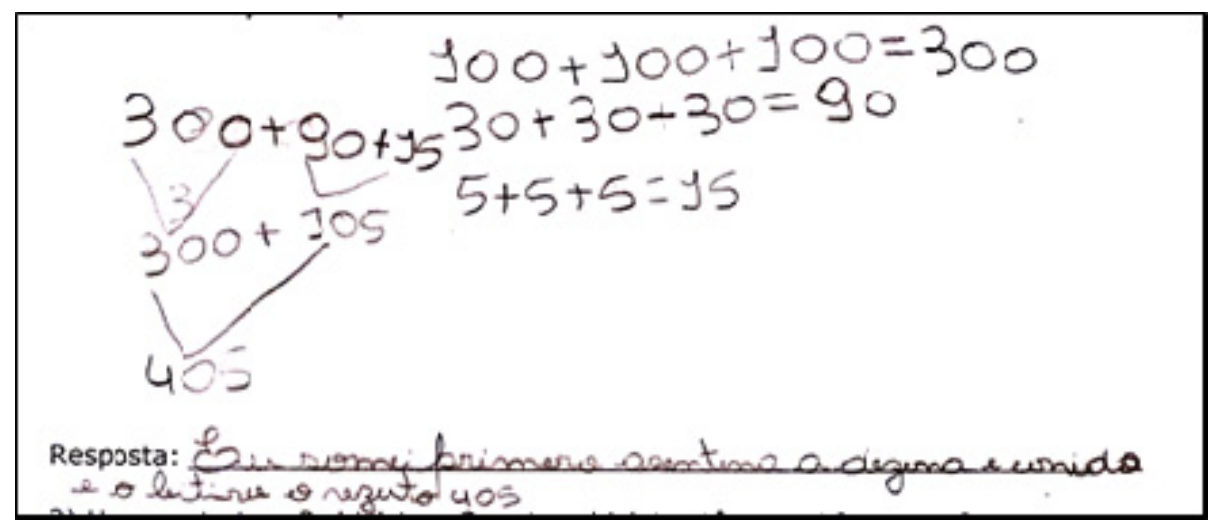

Nesse tratamento estão envolvidos conceitos matemáticos relacionados ao sistema de numeração, como o valor posicional e a ordem de cada algarismo que compõe o número de caixas compradas pela loja. Verificou-se inclusive que esse estudante escreve na resposta o procedimento utilizado "eu somei primeiro a centena, a dezena e unidade e obtive o resultado 
405”,2. Diante disso, o conceito de multiplicação como adição de parcelas iguais fica explicitado na representação das parcelas: $100+100+100 ; 30+30+30$ e $5+5+5$.

Tratamento $2\left(\mathrm{E}_{10}\right)$ :

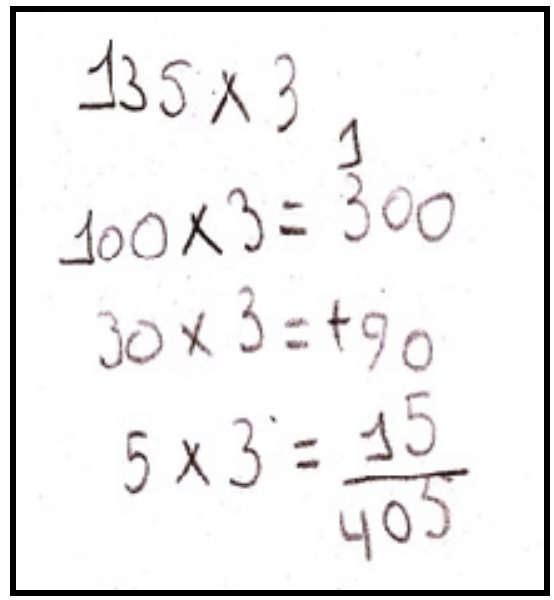

$\mathrm{Na}$ resolução apresentada pelo estudante $\mathrm{E}_{10}$ constatou-se a conversão da situação escrita em língua natural para a linguagem aritmética "135 x 3". Em toda a representação do tratamento é utilizado o símbolo matemático que indica a operação de multiplicação " $\mathrm{x}$ " e a operacionalização é realizada através da decomposição (princípio aditivo do sistema de numeração) do fator $135(100+30+5)$, efetuando três multiplicações parciais $(100 \times 3 ; 30 \times$ 3 e 5 x 3). Por fim, o estudante adiciona os produtos parciais $(300+90+15)$ para obter o produto final 405.

Tratamento $3\left(\mathrm{E}_{12}\right)$ :

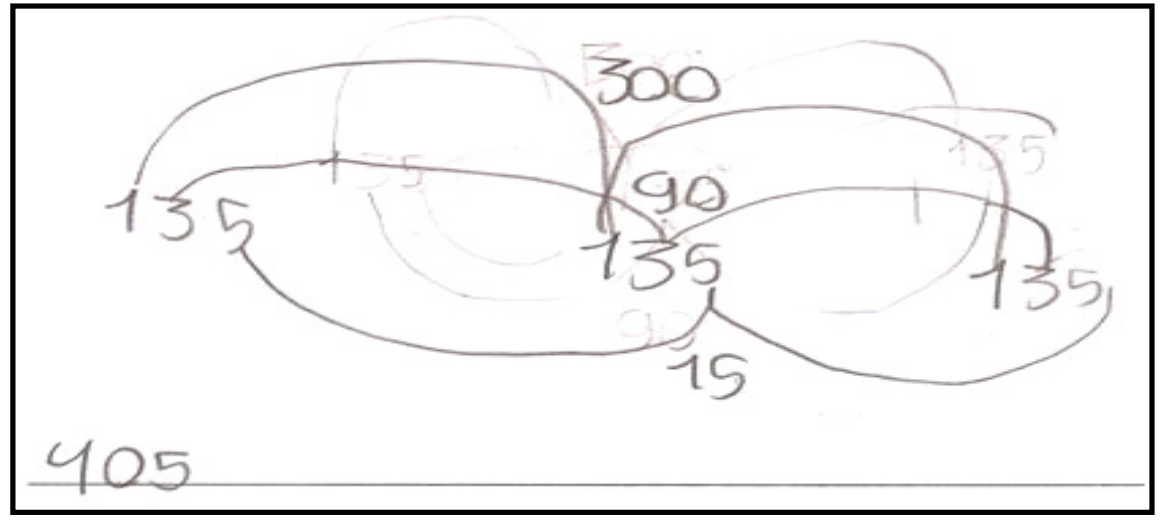

Nesse tratamento é possível perceber uma despreocupação do estudante em utilizar os símbolos matemáticos convencionais. Por meio de um esquema pessoal o mesmo comunica a sua estratégia de cálculo de multiplicação escrevendo três vezes o fator 135, e a seguir, indica 
o 15 como resultado das adições parciais do algarismo das unidades (5), o 90 das dezenas (30) e o 300 das centenas (100). Na sequência, apresenta como resposta final o produto 405, que pela sua estratégia de cálculo, infere-se que foi obtido pela adição de $300+90+15$.

$2^{\text {a }}$ situação: Ana comprou 8 caixas de chocolate. Ela ficou com 32 chocolates. Quantos chocolates tinham em cada caixa?

Essa situação causou muita dificuldade, pois de acordo com Vergnaud (2014) a estrutura do problema indica a resolução por meio de uma divisão. Seis estudantes não resolveram a situação, quatro utilizaram estratégias não convencionais, não encontrando a solução e sete encontraram a solução, sendo que destes, quatro apoiaram-se na multiplicação para resolver a situação.

$\mathrm{Na}$ sequência apresentam-se exemplos de tratamentos utilizados pelos estudantes que resolveram corretamente a situação, sendo que os dois primeiros apoiaram-se na multiplicação e os outros dois apresentam nas estratégias de cálculo conceitos da operação de adição.

Tratamento $1\left(\mathrm{E}_{01}\right)$ :

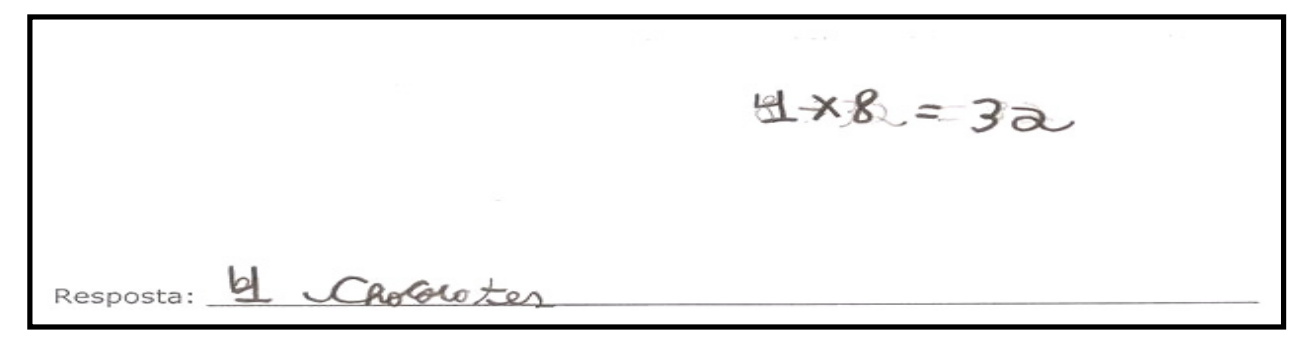

Tratamento $2\left(\mathrm{E}_{04}\right)$ :

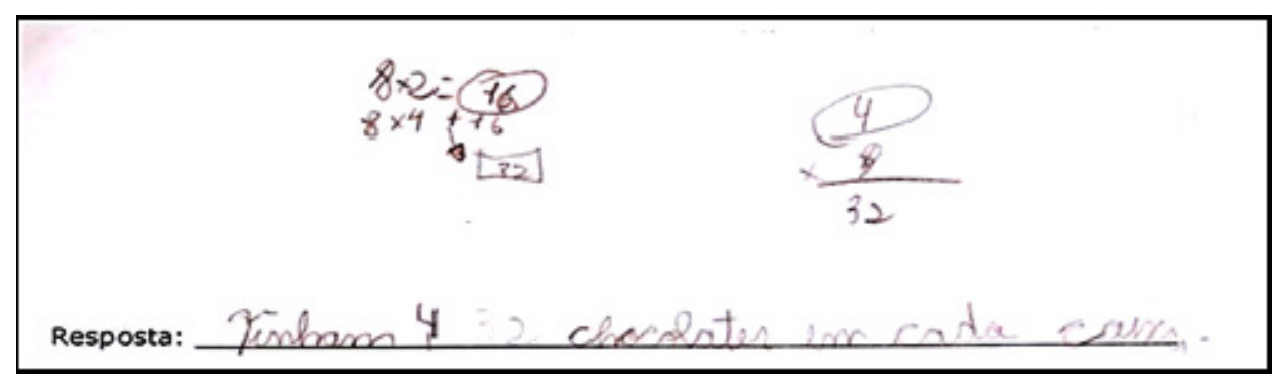

Ao analisar os registros dos estudantes $E_{01}$ e $E_{04}$, verificou-se que a conversão realizada foi apoiada na operação de multiplicação. $O$ estudante $E_{01}$ apresentou a sentença " 4 x $8=32$ ", indicando com um traço, o fator 4 como a solução do problema. Já o estudante $\mathrm{E}_{04}$, além de indicar o fator de solução do problema na sentença matemática, apresenta o tratamento que o 
levou a compreensão e resolução da situação, demonstrando a utilização do conceito de dobro aplicado ao fator e ao produto da multiplicação ao registrar que $8 \times 2=16$ e $16+16=32$ então $8 \times 4=32$.

Tratamento $3\left(\mathrm{E}_{05}\right)$ :

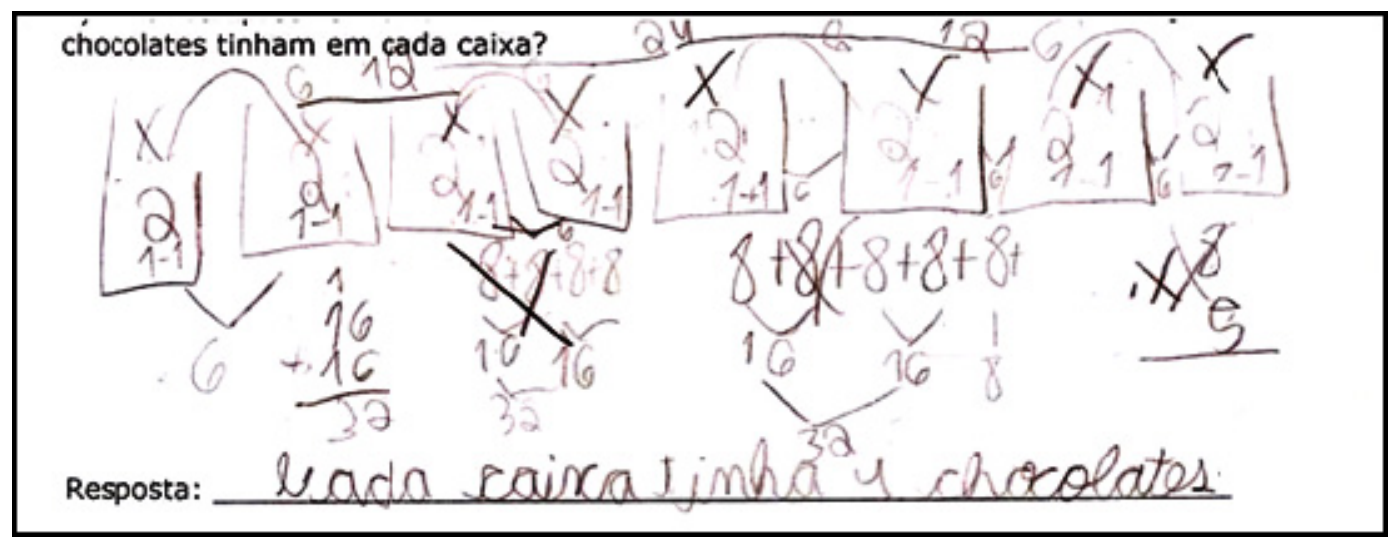

Tratamento $4\left(\mathrm{E}_{13}\right)$ :

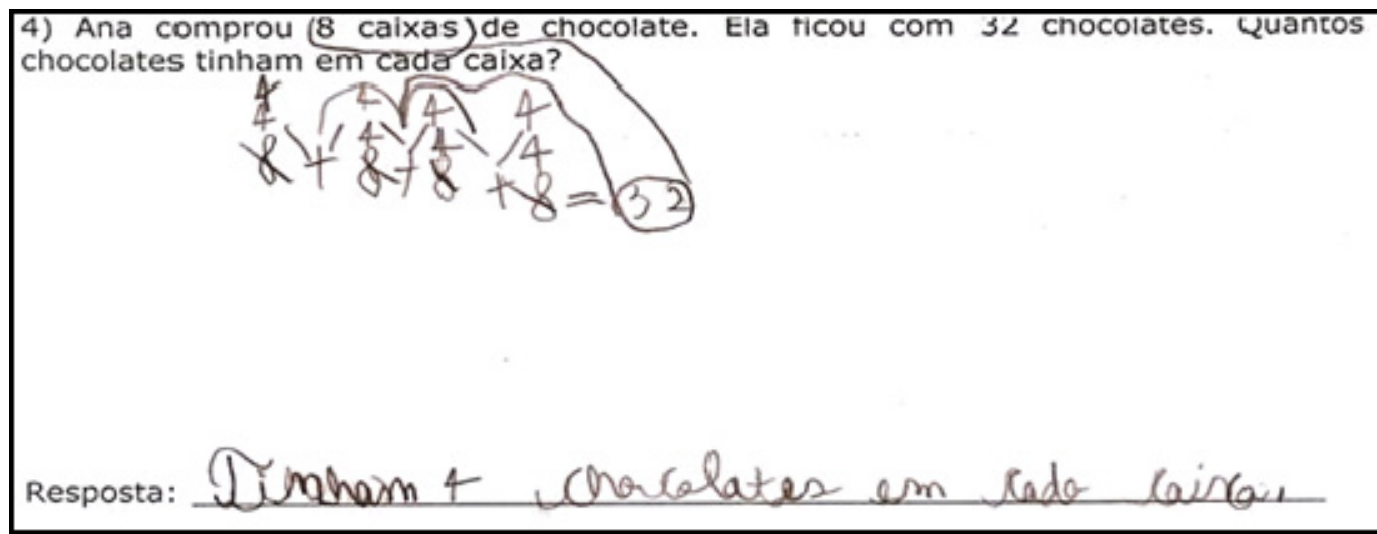

Nas conversões realizadas pelos estudantes $E_{05}$ e $E_{13}$ verificou-se a representação das oito caixas de chocolate e o apoio na operação de adição para encontrar a solução. No registro do estudante $\mathrm{E}_{05}$ constatou-se o princípio da operação de divisão por meio da distribuição indicada nos 8 espaços que representam as caixas de chocolate. Inicialmente fez a distribuição de 2 chocolates em cada espaço, depois fez a distribuição de 1 chocolate e por fim acrescentou 1 chocolate, fechando a distribuição dos 32 chocolates. No registro desse estudante a quantidade de chocolates em cada caixa foi representada pela soma da expressão "2 $+1+1$ ”, totalizando 4 chocolates, sendo que a operação de adição foi utilizada para verificar o total de chocolates (32) nas 8 caixas.

Já no tratamento utilizado pelo estudante $\mathrm{E}_{13}$, observou-se a distribuição das 8 parcelas iguais que representam as caixas de chocolates e a quantidade de chocolates em cada caixa indicadas 
pelo número 4. O resultado final é conferido através da adição de 4 parcelas iguais (8) que foram suprimidas das 8 parcelas iguais anteriores (4) e por fim apresenta uma resposta indicando o número de chocolates que havia em cada caixa.

$3^{\mathbf{a}}$ situação: Elabore uma situação-problema para cada cálculo escrito abaixo:

$$
\begin{aligned}
& 6 \times 3=18 \\
& 3 \times 6=18
\end{aligned}
$$

Nessa situação os alunos deveriam fazer uma tranformação do registro semiótico aritmético para o registro em língua natural. O maior desafio para os estudantes, durante a realização da tarefa, foi identificar o multiplicador e o multiplicando em cada situação, sendo que na primeira o 6 é o multiplicador e o na segunda sentença o 3, pois foram consideradas as seguintes leituras para as sentenças da situação: "seis vezes três igual a dezoito" e " três vezes seis igual a dezoito", de acordo com a linguagem utilizada na escola.

A seguir serão apresentados três pares de conversões realizadas pelos estudantes: as duas primeiras revelam uma não conguência do significado do multiplicador e do multiplicando das sentenças matemáticas; nas outras duas seguintes o enunciado traduz uma sentença diferente da que foi proposta; por fim, duas conversões congruentes com o significado dos termos indicados em cada multiplicação escrita na linguagem aritmética.

Conversões $\left(\mathrm{E}_{09}\right)$ :
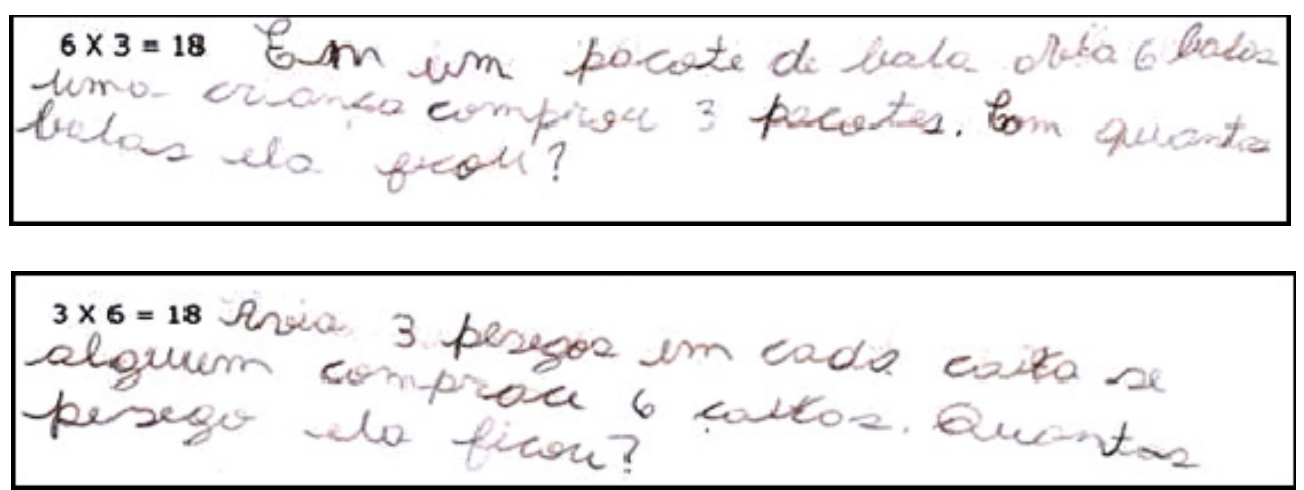

As conversões realizadas pelo estudante $\mathrm{E}_{09}$ demonstram a não-congruência do significado do multiplicando e do multiplicador indicado em cada sentença, considerando a abordagem da escola em relação à leitura da sentença matemática. Com base em Vergnaud (2014), as situações elaboradas pertencem à categoria isomorfismo de medidas, as quais contém uma relação multiplicativa quaternária (pacotes e balas; caixas e pêssegos).

Na primeira situação o multiplicador foi indicado pelo número de pacotes (3), o multiplicando pelo número de balas em cada pacote (6) e a solução do problema o produto 18 (número de balas em 3 pacotes). Logo, a situação escrita na língua natural traduz a sentença 3 × $6=18$ 
(três vezes seis igual a dezoito). Na segunda conversão, o estudante indicou a troca de significados de cada fator, sendo que o 6 assume o papel de multiplicador (número de caixas) e o 3 o papel de multiplicando (número de pêssegos em uma caixa), o que indica a sentença 6 x $3=18$ (seis vezes três igual a dezoito).

Conversões $\left(\mathrm{E}_{05}\right)$ :
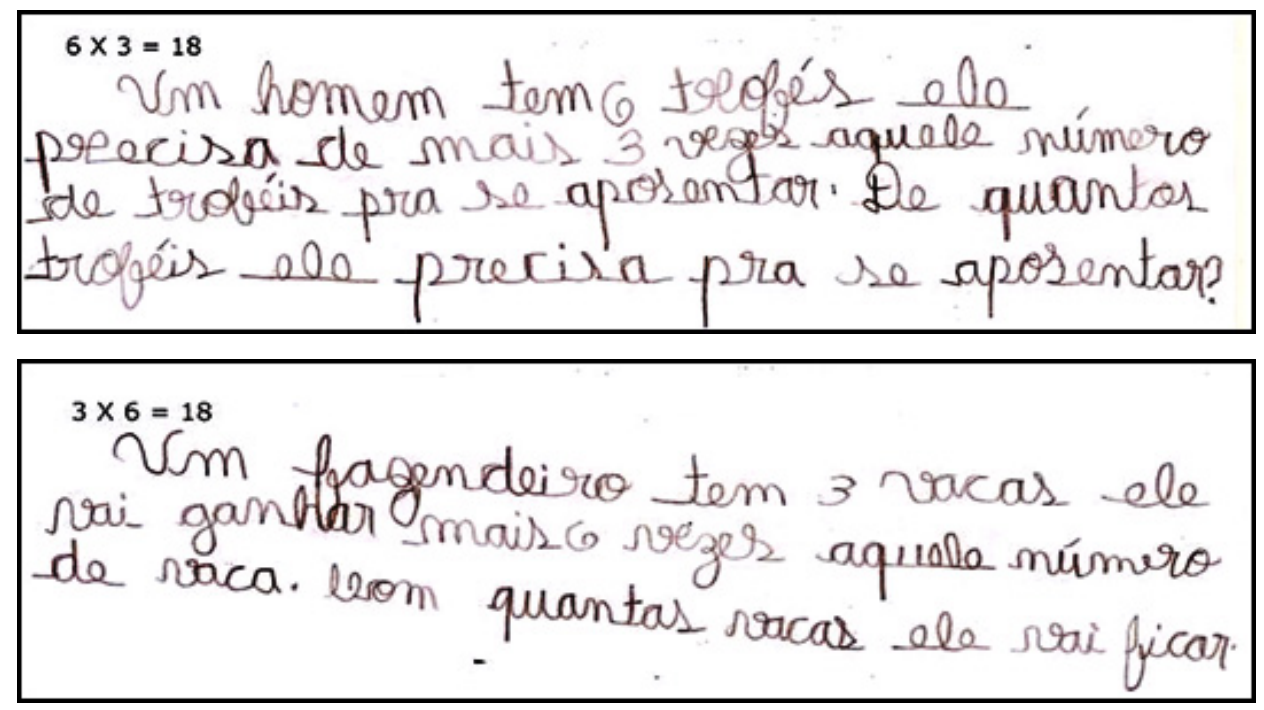

$\mathrm{O}$ estudante $\mathrm{E}_{05}$ procurou elaborar duas situações em que a palavra "vezes" indicasse o operador-escalar ${ }^{3}$, ou seja, a replicação do número de troféus (6) na primeira conversão e o número de vacas (3) na segunda. De acordo com Vergnaud, o estudante fez a tentativa de elaborar um problema onde a correspondência é estabelecida entre duas quantidades, uma medida e um operador-escalar, sendo assim "as expressões linguísticas 'três vezes mais' e 'três vezes menos' estão inevitavelmente presentes no enunciado dessa forma de relação" (2014, p. 263). Contudo, ao utilizar as expressões "mais 3 vezes" e "mais 6 vezes" o estudante elaborou uma situação que traduz as sentenças matemáticas: $6+(3 \times 6)$ e $3+(6$ x 3), demonstrando um equívoco quanto a congruência do significado de operador-escalar.

Conversões $\left(\mathrm{E}_{10}\right)$ :

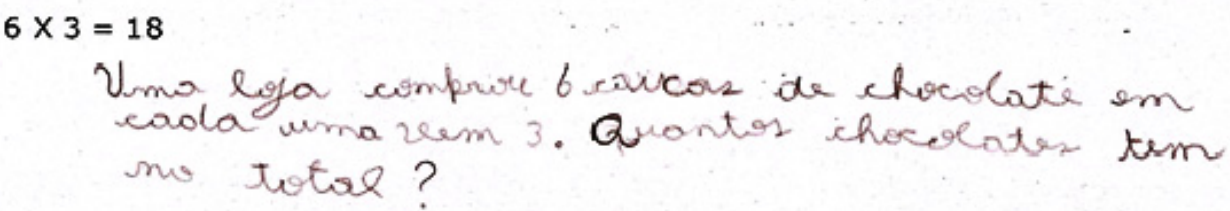

${ }^{3}$ Unidade constante, sem dimensão, que indica o número de replicações relacionado a determinada quantidade. REVEMAT. Florianópolis (SC), v.10, n. 1, p. 52-64, 2015. 


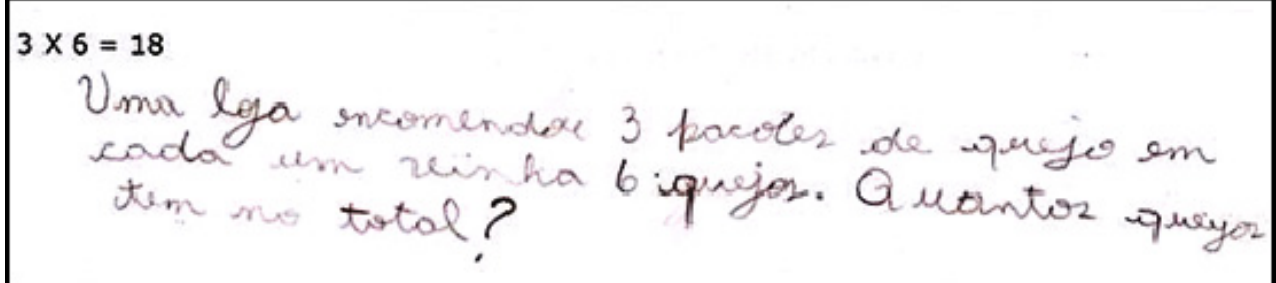

$\mathrm{O}$ estudante $\mathrm{E}_{10}$ elaborou duas situações da categoria isomorfismo de medidas, demonstrando congruência em relação ao significado do multiplicador e multiplicando nas duas conversões realizadas.

Nesse contexto, ao desconsiderar o significado do multiplicando e do multiplicador nas situações propostas podem ocorrer alguns equívocos quanto ao uso de expressões como "vezes" e "multiplicado por", atribuídas ao significado do símbolo "x", utilizado para representar a operação. Por isso, cabe enfatizar o significado do multiplicando e do multiplicador, independente da opção da expressão utilizada, de maneira que a significação da operação de multiplicação seja mantida (CRUSIUS, GOMES, DANYLUK, [s.d.]).

A partir do estudo realizado, verificou-se nas produções dos estudantes uma diversidade de interpretações, de representações e de transformações de situações matemáticas, que podem constituir-se em material de estudo no contexto escolar.

\section{Algumas implicações pedagógicas}

Nesta análise constatou-se que os estudantes utilizaram diferentes tratamentos ao resolverem as situações do campo multiplicativo e acionaram conhecimentos relacionados ao conceito de adição, multiplicação e ao significado dos termos (multiplicador, multiplicando e operadorescalar) na situação de conversão proposta.

Nesse contexto, a Teoria dos Campos Conceituais traz contribuições importantes para os processos de ensino e de aprendizagem da Matemática, porque ressalta a importância da utilização de uma variedade de situações para a apropriação dos significados e a formação de conceitos relacionados às operações aritméticas básicas, pois é "através das situações e dos problemas que se pretendem resolver é como um conceito adquire sentido para a criança" (VERGNAUD, 1990, p. 1, tradução nossa).

Por outro lado, a abordagem das transformações de registros de representação semiótica (tratamentos e conversões), que demonstram diferentes aspectos relacionados a um mesmo conceito matemático, constitui-se em mais uma possibilidade de potencializar a compreensão em matemática na sala de aula. Pois, como afirma Duval, nos sujeitos "em período de 
desenvolvimento e formação inicial, o progresso de aquisição de conhecimentos matemáticos depende da coordenação de registros de representação semiótica" (2003, p. 29).

Assim, a interpretação do professor diante das estratégias de cálculo utilizadas pelos estudantes é fundamental para identificar os saberes matemáticos veiculados em cada situação, além de possibilitar a construção de situações de aprendizagem que priorizem a compreensão dos conceitos matemáticos. Dessa forma, surgem formas de problematizar as regras procedimentais de um algoritmo convencional, por exemplo, a partir dos conhecimentos já adquiridos e dos procedimentos não convencionais conhecidos pelas crianças.

A diversidade de exemplos de transformações - tratamentos e conversões - identificados nesse estudo mostra a importância da análise não só das estruturas dos problemas envolvendo o campo conceitual multiplicativo, mas principalmente das estratégias de resolução utilizadas pelos estudantes, o que possibilita revelar ao professor tanto a aprendizagem como o nível de desenvolvimento intelectual.

\section{Referências}

BRASIL. Ministério da Educação e do Desporto. Secretaria de Educação Fundamental. Parâmetros curriculares nacionais primeiro e segundo ciclos do ensino fundamental: Matemática. Brasília: MEC/SEF, 1997.

CRUSIUS, Maria Fialho (Org.); GOMES, Carmem H. P.; DANYLUK, Ocsana. Sistema de numeração e operações em diversas bases. Passo Fundo: Gráfica e Editora da UPF, [s.d.].

DUVAL, Raymond. Registro de representação semiótica e o funcionamento cognitivo da compreensão em matemática. In: MACHADO, Silvia D. A. (org.). Aprendizagem em matemática: registros de representação semiótica. Campinas: Papirus, 2003. p.11-34.

Semiósis e pensamento humano: registro semiótico e aprendizagens intelectuais (fascículo I). Tradução de Lênio Fernandes Levy e Marisa Rosâni Abreu da Silveira. São Paulo: Livraria da Física, 2009.

VERGNAUD, Gérard. A criança, a matemática e a realidade: problemas do ensino da matemática na escola elementar. Ed. Rev. Curitiba: Ed. da UFPR, 2014.

La Teoria de Los Campos Conceptuales. Tradução de Juan D. Godino. In:

Recherches en Didactique des Mathématiques, v. 10, n. 2, p. 133-170, 1990. Disponível em: $<$ http://fundesuperior.org/Articulos/Pedagogia/Teoria_campos_ conceptuales.pdf $>$. Acesso em: 03 fev. 2015. 